\title{
Procedures and recommended times in the care process of the patient with pancreatic cancer: PAN-TIME consensus between scientific societies
}

\author{
R. Vera ${ }^{1}$ - A. Ferrández ${ }^{2}$ - C. J. Ferrer ${ }^{3}$ - C. Flores ${ }^{4}$ - C. Joaquín ${ }^{5}$. \\ S. López ${ }^{6} \cdot$ T. Martín $^{7}$ - E. Martín ${ }^{8}$ - M. Marzo ${ }^{9}$ A. Sarrión ${ }^{10}$ • E. Vaquero ${ }^{11}$. \\ A. Zapatero ${ }^{12} \cdot$ J. Aparicio ${ }^{1}$
}

Received: 16 December 2016/Accepted: 29 December 2016/Published online: 19 January 2017

(c) Federación de Sociedades Españolas de Oncología (FESEO) 2017

\begin{abstract}
Purpose Pancreatic cancer (PC) is a disease with bad prognosis. It is usually diagnosed at advanced stages and its treatment is complex. The aim of this consensus document was to provide recommendations by experts that would ameliorate PC diagnosis, reduce the time to treatment, and optimize PC management by interdisciplinary teams.

Methods As a consensus method, we followed the modified Delphi methodology. A scientific committee of experts provided 40 statements that were submitted in two rounds to a panel of 87 specialists of 12 scientific societies.

Results Agreement was reached for 39 of the 40 proposed statements (97.5\%).

Conclusions Although a screening of the asymptomatic population is not a feasible option, special attention to potential symptoms during primary care could ameliorate early diagnostic. It is especially important to decrease the period until diagnostic tests are performed. This consensus
\end{abstract}

The original version of this article was revised due to a retrospective Open Access order.

This Pan-TIME Consensus is being simultaneously published in the journals from the scientific societies that have participated on the consensus statement.

\footnotetext{
R. Vera

ruth.vera.garcia@cfnavarra.es

Spanish Society of Medical Oncology, Madrid, Spain

Spanish Society of Pathological Anatomy, Madrid, Spain

Spanish Society of Radiation Oncology, Madrid, Spain

4 Spanish Society of General and Family Physicians, Madrid, Spain

5 Spanish Society of Endocrinology and Nutrition, Madrid, Spain
}

could improve survival in PC patients by decreasing the time to diagnose and time to treatment and by the implementation of multidisciplinary teams.

Keywords Pancreatic neoplasms - Delphi technique . Interdisciplinary communication - Early detection of cancer - Time-to-treatment

\section{Introduction}

Pancreatic cancer (PC) is a disease with a poor prognosis. The median overall survival from diagnosis is 4.6 months in patients with metastatic disease and 10-12 months after resection [1]. Unlike other cancers, which have improved survival in recent decades [2], the prognosis of this disease has not improved in the past 20 years, and its incidence and high mortality have remained practically constant [3]. PC is the fourth most common tumor in Europe both in men, after lung, colorectal, and prostate cancer, as in women, after breast, colorectal, and lung cancer [2].

Most patients with CP develop a locally advanced or metastatic disease during an asymptomatic phase of the tumor [3]. The initial symptoms are non-specific, which

\footnotetext{
6 Spanish Society of Surgical Oncology, Madrid, Spain

7 Spanish Society of Medical Radiology/Spanish Society of Abdominal Radiology, Madrid, Spain

8 Spanish Association of Surgeons, Madrid, Spain

9 Spanish Society of Family and Community Medicine, Madrid, Spain

10 Spanish Society of Primary Care Physicians, Madrid, Spain

11 Spanish Association of Gastroenterology, Madrid, Spain

12 Spanish Society of Internal Medicine, Madrid, Spain
} 
may lengthen the diagnostic process and contribute to the fact that most patients are not diagnosed until advanced stages of the disease (up to $80-85 \%$ ), when the tumor has metastasized [4]. Surgical resection is possible in only $15-20 \%$ of patients, but even with surgical treatment, survival at 5 years is approximately $20 \%$ [3]. Survival may increase when patients are treated by multidisciplinary teams, in centers with a large number of cases, with experience in the diagnosis and treatment of the disease $[5,6]$.

The Spanish Society of Medical Oncology (SEOM) is aware of the importance of an early PC diagnosis and of an adequate and comprehensive treatment by multidisciplinary teams. Therefore, SEOM has led the development of a consensus with other specialties involved in the care of these patients, including experts of recognized prestige from 11 other scientific societies.

The aim of this study was to provide a consensus document (PAN-TIME consensus), as a reference for the scientific community, detailing the PC patient care process. The consensus also recommends maximum times that should not be exceeded in the different phases of the diagnostic process or in the initiation of the different treatment modalities. In addition, the consensus highlights the importance of multidisciplinary management and identifies opportunities for improving PC patients' care.

\section{Materials and methods}

\section{Design}

The consensus method chosen was a modified Delphi method following recommendations from RAND/UCLA $[7,8]$. A scientific committee was formed consisting of two members of SEOM and one member of each of ten other scientific societies: Spanish Society of Medical Radiology, Spanish Society of Radiotherapy and Oncology, Spanish Gastroenterology Association, Spanish Society of Anatomic Pathology, Spanish Society of Internal Medicine, Spanish Society of Family and Community Medicine, Spanish Society of Primary Care Physicians, Spanish Society of General and Family Physicians, Spanish Society of Surgeons, Spanish Society of Surgical Oncology, Spanish Society of Endocrinology and Nutrition.

Goals and consensus design were discussed face-to-face. A bibliographic search was carried out and 40 items were written in a consensual way. These items reflected the current situation of PC management and included recommendations on aspects related to care process or that were not answered in the scientific literature. Forty items were agreed on in six areas: general aspects (4 items), pre-diagnosis (5 items), diagnosis (12 items), treatment (12 items), follow-up (6 items), and recommendations for future improvement (1 item).
Then the members of the expert panel were chosen who were to evaluate these 40 items. The panelists were selected by the scientific societies themselves taking into account their experience, degree of knowledge, or relationship with PC in their professional field. The number of panelists proposed was ten for each scientific society, with the exception of primary care societies. Those societies would have four representatives each so that the weight of the specialty would be similar to that of the rest of the participating societies.

Subsequently, the questionnaire was sent to the panelists and was answered on line in two rounds. Agreement was assessed with a nine-point ordinal scale $(1=$ full disagreement, $9=$ full agreement). Responses were grouped into three categories: $1-3=$ disagree; $4-6=$ neither agree nor disagree and; $7-9=$ agree.

Statements that did not reach consensus were re-evaluated in a second round, with the wording modified as they were considered as misleading. Between rounds, panelists were informed of the detailed distribution of responses from the first analysis. Panelists who did not respond to the first round were excluded from the following analysis.

\section{Analysis}

Consensus was reached if the median of the responses was over 7 or below 3 and less than one-third of the panelists voted outside the ranges and the interquartile range (IQR) should be less than 4 .

Results are shown in Tables 1, 2, 3, 4, 5 and 6 as number of votes with median of the answers, IQR, degree of agreement between panelists and final result regarding agreement or disagreement for each item. The degree of agreement indicates the percentage of panelists who voted within the median range (1-3, 4-6, 7-9).

Items in which panellists did not reach consensus in the first round ( 3 assertions) were re-evaluated in a second round. Items' wording was modified as it was considered that agreement was not reached due to misleading wording.

\section{Results}

The final number of panelists was 97, with the following representation: 10 experts each from the Spanish Society of Medical Oncology, the Spanish Society of Medical Radiology, the Spanish Society of Radiation Oncology, the Spanish Association of Gastroenterology, Spanish Society of Pathological Anatomy, of the Spanish Society of Internal Medicine and of the Spanish Association of Surgeons; 4 experts from the Spanish Society of Family and Community Medicine; 3 experts each from the Spanish Society of Primary Care Physicians and the Spanish Society of 
Table 1 Section I results: general aspects

\begin{tabular}{|c|c|c|c|}
\hline & $\begin{array}{l}\text { Median } \\
(\mathrm{IQR})\end{array}$ & $\begin{array}{l}\text { Agreement } \\
(\%)\end{array}$ & Result \\
\hline $\begin{array}{l}\text { 1. Pancreatic cancer has been classically associated with a certain nihilistic medical approach, } \\
\text { given the diagnostic difficulties and the limited therapeutic options }\end{array}$ & $8(6-8)$ & 69.7 & $\begin{array}{l}\text { First round } \\
\text { agreement }\end{array}$ \\
\hline $\begin{array}{l}\text { 2. Recently improvements in diagnostic techniques and new therapeutic options have improved the } \\
\text { overall care of the patient with PC. Thus, a call to end this perception should be desirable }\end{array}$ & $7(7-8)$ & 78.3 & $\begin{array}{l}\text { Second round } \\
\text { agreement }\end{array}$ \\
\hline $\begin{array}{l}\text { 3. The possibility of identifying combinations of symptoms with a higher positive predictive value } \\
\text { that may lead to suspicion of cancer, together with a continuous improvement in the capacity of } \\
\text { diagnostic and staging techniques are key objectives in the diagnostic phase }\end{array}$ & $8(7-8)$ & 86.7 & $\begin{array}{c}\text { Second round } \\
\text { agreement }\end{array}$ \\
\hline $\begin{array}{l}\text { 4. There are currently not enough data to perform systematic screening for PC in asymptomatic } \\
\text { patients. However, screening may be possible in some high-risk patients in the future }\end{array}$ & $9(7-9)$ & 85.4 & $\begin{array}{l}\text { First round } \\
\text { agreement }\end{array}$ \\
\hline
\end{tabular}

$I Q R$ interquartile range

Table 2 Section II results: prediagnostic

\begin{tabular}{|c|c|c|c|}
\hline & $\begin{array}{l}\text { Median } \\
\text { (IQR) }\end{array}$ & $\begin{array}{l}\text { Agreement } \\
(\%)\end{array}$ & Result \\
\hline $\begin{array}{l}\text { 5. The primary care physician is usually the first to contact the patient with symptoms or signs due } \\
\text { to pancreatic cancer. It is crucial that PC physicians exercise a high degree of suspicion to achieve } \\
\text { a faster diagnosis of the disease }\end{array}$ & $8(6-9)$ & 73.0 & $\begin{array}{c}\text { First round } \\
\text { agreement }\end{array}$ \\
\hline $\begin{array}{l}\text { 6. A smaller proportion of patients with symptoms or signs due to pancreatic cancer are initially } \\
\text { diagnosed by gastroenterologists, surgeons or internists (without primary care) after obstructive } \\
\text { jaundice or acute pancreatitis, often with other symptoms like weight loss }\end{array}$ & $8(5-9)$ & 71.9 & $\begin{array}{c}\text { First round } \\
\text { agreement }\end{array}$ \\
\hline $\begin{array}{l}\text { 7. In general, the initial symptoms are nonspecific, not very striking or may also be due to other very } \\
\text { diverse, sometimes banal pathologies. Even in these suspected cases, the diagnosis is difficult and } \\
\text { it may take several months until the first consultation with the doctor and several more months } \\
\text { before the diagnosis is established }\end{array}$ & $8(8-9)$ & 95.5 & $\begin{array}{c}\text { First round } \\
\text { agreement }\end{array}$ \\
\hline $\begin{array}{l}\text { 8. The onset of diabetes without metabolic syndrome (especially in individuals older than } 50 \text { years), } \\
\text { non-specific gastrointestinal symptoms or involuntary weight loss are findings that may facilitate } \\
\text { suspicion of PC }\end{array}$ & $8(7-9)$ & 79.8 & $\begin{array}{l}\text { First round } \\
\text { agreement }\end{array}$ \\
\hline $\begin{array}{l}\text { 9. In primary care, the presence of jaundice in a patient aged over } 40 \text { years should be a reason to } \\
\text { refer the patient to the emergency room. In patients aged over } 60 \text { years, weight loss associated } \\
\text { with other gastrointestinal changes (especially abdominal pain and diarrhea), back pain or new- } \\
\text { onset diabetes should be a reason for referral to the specialist within } 15 \text { days }\end{array}$ & $8(8-9)$ & 93.3 & $\begin{array}{c}\text { First round } \\
\text { agreement }\end{array}$ \\
\hline
\end{tabular}

$I Q R$ interquartile range

General and Family Physicians; 9 experts from the Spanish Society of Surgical Oncology, and 8 from the Spanish Society of Endocrinology and Nutrition.

Of the 97 panelists selected, 8 did not respond in the first round and were excluded from the following analysis. In the second round there were two who did not respond. There were thus 87 panelists whose responses were taken into account by the scientific committee to reach consensus.

Of the total of 40 items raised, there was consensus in the agreement in 37 of them in the first round. Consensus was reached in the agreement in two of the three assertions that were questioned in the second round, so after the two rounds agreement was reached in 39 of the 40 issues $(97.5 \%$ ) (Tables $1,2,3,4,5,6)$. Table 7 summarizes the main recommendations agreed by the panel of experts.

\section{Discussion}

PC is the fourth cancer with a higher mortality in Europe; it has a poor prognosis and its survival has not improved in the past decades [3]. For this reason, a document of practical recommendations elaborated by all the specialties involved could be of great help to improve the care of patients with PC.

With the ultimate goal of providing recommendations to improve patients' survival and quality of life, the scientific committee grouped the items to discuss on four general 
Table 3 Section III results: diagnosis

\begin{tabular}{|c|c|c|c|}
\hline & $\begin{array}{l}\text { Median } \\
\text { (IQR) }\end{array}$ & $\begin{array}{l}\text { Agreement } \\
(\%)\end{array}$ & Result \\
\hline $\begin{array}{l}\text { 10. The standard diagnostic procedure should include first steps anamnesis, physical examination, } \\
\text { analytical and ultrasound tests }\end{array}$ & $9(8-9)$ & 91.0 & $\begin{array}{l}\text { First round } \\
\text { agreement }\end{array}$ \\
\hline $\begin{array}{l}\text { 11. When the ultrasound request specifies that it is intended to rule out pancreatic cancer, if it is not } \\
\text { diagnostic (for lack of visualization or for other reasons) there must be a protocol that leads } \\
\text { directly to the performance of an MCT scan }\end{array}$ & $9(8-9)$ & 97.8 & $\begin{array}{c}\text { First round } \\
\text { agreement }\end{array}$ \\
\hline $\begin{array}{l}\text { 12. The availability and speed to obtain complementary examinations, and specifically the } \\
\text { ultrasound, differ in different places, and the approach of the primary care physician must be } \\
\text { decided accordingly }\end{array}$ & $8(7-9)$ & 79.8 & $\begin{array}{l}\text { First round } \\
\text { agreement }\end{array}$ \\
\hline $\begin{array}{l}\text { 13. In primary care, if the availability of explorations is limited, when there is presence jaundice or } \\
\text { acute pain that causes suspicion of pancreatitis, the patient can be referred to the Emergency Unit } \\
\text { to perform diagnostic tests on an urgent basis }\end{array}$ & $9(8-9)$ & 92.1 & $\begin{array}{c}\text { First round } \\
\text { agreement }\end{array}$ \\
\hline $\begin{array}{l}\text { 14. When there is a substantial delay in the performance of ultrasound, while on primary care, the } \\
\text { request should specify a suspicion of pancreatic cancer, which should ensure a prompt scanning by } \\
\text { the diagnostic imaging service }\end{array}$ & $8(8-9)$ & 94.4 & $\begin{array}{c}\text { First round } \\
\text { agreement }\end{array}$ \\
\hline $\begin{array}{l}\text { 15. Ultrasound has a low sensitivity and detects tumors with a resolution of } 2 \mathrm{~cm} \text { so that most small } \\
\text { tumors are not detected. However, in general, it must be performed before moving towards other } \\
\text { tests since it does detect advanced tumors and/or with liver metastases }\end{array}$ & $8(6-9)$ & 71.9 & $\begin{array}{l}\text { First round } \\
\text { agreement }\end{array}$ \\
\hline $\begin{array}{l}\text { 16. Negative ultrasound results do not rule out pancreatic cancer. If the symptoms are sufficiently } \\
\text { indicative of this diagnosis, the patient should be referred to the specialist for a MCT scan }\end{array}$ & $9(8-9)$ & 96.6 & $\begin{array}{l}\text { First round } \\
\text { agreement }\end{array}$ \\
\hline $\begin{array}{l}\text { 17. Suspected cases while in primary care should be referred to a hospital with interdisciplinary } \\
\text { tumor committees with experience in the diagnosis and treatment of pancreatic cancer }\end{array}$ & $9(7-9)$ & 82.0 & $\begin{array}{l}\text { First round } \\
\text { agreement }\end{array}$ \\
\hline $\begin{array}{l}\text { 18. Regardless of how the diagnosis has been made (ultrasound or MCT) and in what type of unit it } \\
\text { is carried, every patient with pancreatic cancer should be given an MCT with a specific protocol to } \\
\text { assess the relationship of the tumor with the mesenteric vessels and to assess its resectability }\end{array}$ & 9 (9-9) & 97.8 & $\begin{array}{l}\text { First round } \\
\text { agreement }\end{array}$ \\
\hline $\begin{array}{l}\text { 19. Upon suspicion of pancreatic cancer, the diagnostic study of the specialized unit should be } \\
\text { completed within } 2 \text { weeks }\end{array}$ & $9(8-9)$ & 94.4 & $\begin{array}{l}\text { First round } \\
\text { agreement }\end{array}$ \\
\hline $\begin{array}{l}\text { 20. Histological confirmation of the diagnosis should always be obtained, with the exception of } \\
\text { surgical cases in which histological examination will be performed with operative samples }\end{array}$ & $8(7-9)$ & 85.4 & $\begin{array}{l}\text { First round } \\
\text { agreement }\end{array}$ \\
\hline $\begin{array}{l}\text { 21. Each reference center should establish a multidisciplinary tumor committee (MDC) to which all } \\
\text { patients are presented }\end{array}$ & $9(8.5-9)$ & 97.8 & $\begin{array}{l}\text { First round } \\
\text { agreement }\end{array}$ \\
\hline
\end{tabular}

$I Q R$ interquartile range

topics: (a) general aspects and pre-diagnosis; (b) diagnosis; (c) treatment, and (d) monitoring.

\section{General aspects and pre-diagnosis}

The panelists agree that PC has been classically associated with a certain nihilistic medical approach, given the diagnostic difficulties and the limited therapeutic options. In this sense, PC mortality has not declined in recent decades in Europe despite the fact that mortality from other cancers has fallen by $26 \%$ in men and $20 \%$ in women since 1990 [2]. The skepticism that could be appreciated among Spanish physicians has also been verified in studies in other countries, where surgery may be aimed at only a small number of patients with PC [9]. Panelists make a call to end this perception and highlight improvements in diagnostic techniques and new therapeutic options that can improve the overall care of the patient with PC [5].
Panelists also agree that there are currently not enough data to perform systematic screening for PC in asymptomatic patients. However, screening may be possible in some high-risk patients in the future. High-risk patients are those with hereditary factors predisposing to the development of the disease. However, only $5-10 \%$ of PC cases were related to hereditary factors $[3,10]$. The most frequent mutation associated with $\mathrm{PC}$ is a mutation of breast cancer gene 2 (BRCA2), which is also associated with breast and ovarian cancer [11], although other mutations are also associated with PC [3]. In addition, there are other family syndromes associated with PC such as PeutzJeghers syndrome, hereditary pancreatitis, hereditary nonpolyposis colorectal cancer (Lynch syndrome), and ataxiatelangiectasia, among others [3].

Screening of some mutations in high-risk PC patients, such as CDKN2A, BRCA1/2 or PALB2 mutations, has been shown to be an effective strategy in detecting a greater number of tumors in phases in which they are still 
Table 4 Section IV results: treatment

\begin{tabular}{|c|c|c|c|}
\hline & $\begin{array}{l}\text { Median } \\
\text { (IQR) }\end{array}$ & $\begin{array}{l}\text { Agreement } \\
(\%)\end{array}$ & Result \\
\hline $\begin{array}{l}\text { 22. In all cases, the treatment to be applied (or, if appropriate, the conduct of new diagnostic } \\
\text { examinations) should be established by the MDC constituted in the center }\end{array}$ & $9(8-9)$ & 91.0 & First round agreement \\
\hline $\begin{array}{l}\text { 23. The MDC should always include specialists in medical and radiotherapeutic oncology, } \\
\text { surgery, pathology, radiology, digestive apparatus, ecoendoscopy and nutrition/dietetics. } \\
\text { Optionally, each center may opt for the additional participation of specialists in critical care } \\
\text { (ICU/anesthesia), endocrinology, interventional radiology or other specialties }\end{array}$ & $9(7-9)$ & 88.8 & First round agreement \\
\hline $\begin{array}{l}\text { 24. Centers that do not have MDC should refer the patient with a clear diagnosis or suspicion } \\
\text { of pancreatic cancer to a referral center that does }\end{array}$ & $9(8-9)$ & 88.8 & First round agreement \\
\hline 25. MDC decision-making sessions should be held at least weekly & $9(7-9)$ & 79.8 & First round agreement \\
\hline $\begin{array}{l}\text { 26. Overall, the maximum time elapsed from the definitive diagnosis (including preliminary } \\
\text { staging) to the start of treatment should be } 15 \text { days }-1 \text { month }\end{array}$ & $9(8-9)$ & 92.1 & First round agreement \\
\hline $\begin{array}{l}\text { 27. In approximately } 20-30 \% \text { of patients the decision of CMD may be surgical treatment } \\
\text { with curative intent. In such a case, the maximum time elapsed from decision to } \\
\text { intervention should be } 4 \text { weeks, but it should be attempted to reduce that time limit as much } \\
\text { as possible, ideally less than } 15 \text { days }\end{array}$ & $9(8-9)$ & 94.4 & First round agreement \\
\hline $\begin{array}{l}\text { 28. Treatment of adjuvant chemotherapy should be initiated not before } 3-4 \text { weeks from the } \\
\text { intervention nor later than } 6-8 \text { weeks after the intervention, unless the patient's recovery is } \\
\text { insufficient }\end{array}$ & $9(8-9)$ & 88.8 & First round agreement \\
\hline $\begin{array}{l}\text { 29. In } 70-80 \% \text { of patients who are not candidates for curative intent surgery, treatment should } \\
\text { be applied or coordinated by medical oncology specialists. The maximum time elapsed } \\
\text { from the decision to the start of treatment should be } 7 \text { days for chemotherapy and } 15 \text { days } \\
\text { for chemoradiotherapy }\end{array}$ & $8(7-9)$ & 84.3 & First round agreement \\
\hline $\begin{array}{l}\text { 30. Concomitant chemotherapy and radiotherapy treatment will be scheduled according to the } \\
\text { planning of the latter, but should not be delayed for more than } 2 \text { weeks }\end{array}$ & $8(7-9)$ & 91.0 & First round agreement \\
\hline $\begin{array}{l}\text { 31. Some resection cases can be treated with preoperative chemotherapy or } \\
\text { chemoradiotherapy. In this case, the maximum time elapsed from the decision to the start of } \\
\text { treatment should be } 4 \text { weeks, but an attempt should be made to shorten the time limit as } \\
\text { much as possible, to be less than } 15 \text { days }\end{array}$ & $8(8-9)$ & 93.3 & First round agreement \\
\hline $\begin{array}{l}\text { 32. The initiation of palliative chemotherapy should not be delayed for more than } 7 \text { days, if } \\
\text { the patient's condition allows it }\end{array}$ & $8(7-9)$ & 76.4 & First round agreement \\
\hline $\begin{array}{l}\text { 33. The treatment, both surgical and medical, should be performed in tertiary centers that } \\
\text { have experienced teams and access to all the complementary services that may be needed: } \\
\text { ICU, interventional vascular treatment, etc. }\end{array}$ & $9(8-9)$ & 89.9 & First round agreement \\
\hline
\end{tabular}

$I Q R$ interquartile range

resectable [12, 13]. Screening of patients with a family history of PC may also be useful, although the benefit is more limited [13]. In practice, screening has been proposed in people with two or more first-degree relatives with PC with mutations associated with this disease or with a family history with a high genetic load of PC (such as two affected relatives, one of them first degree). Screening is also recommended in patients with inherited PC-associated syndromes such as Peutz-Jeghers syndrome or hereditary chronic pancreatitis associated with mutations in the PRSS1 gene [10].

In most cases it is suggested to start screening at age 50, except in patients with hereditary pancreatitis who are advised to start at age 40 .

Magnetic resonance imaging, echo-endoscopy or magnetic resonance cholangiopancreatography are proposed as screening tests [10].
On the other hand, about $90 \%$ of PC cases are sporadic. The risk factor most clearly related to this type of cancer is tobacco. Other risk factors that have been described are obesity, diabetes, excessive consumption of alcohol or red meat, low fruit consumption, chronic pancreatitis, or infection with Helicobacter pylori [3, 10]. These risk factors may be subject to change, which is a good opportunity to design preventive measures.

Biomarkers are being investigated that could in the future detect high-risk candidates for screening [4]. At the moment, CA 19-9 is the only serum biomarker useful for the diagnosis and follow-up of PC. As a diagnostic marker it offers a sensitivity of $79-81 \%$ and a specificity of $80-90 \%$ in symptomatic patients. However, given its low positive predictive value, its use as a biomarker for PC screening in asymptomatic individuals is not indicated [5]. In patients diagnosed with PC, CA 19-9 can be used to 
Table 5 Section V results: follow-up

\begin{tabular}{|c|c|c|c|}
\hline & $\begin{array}{l}\text { Median } \\
\text { (IQR) }\end{array}$ & $\begin{array}{l}\text { Agreement } \\
(\%)\end{array}$ & Result \\
\hline 34. The follow-up to be performed must be defined by the MDC & $8(7-9)$ & 85.4 & First round agreement \\
\hline $\begin{array}{l}\text { 35. In order to avoid repetitions and redundancies, each center must establish a consensual } \\
\text { protocol to define which specialties or units assume the follow-up of the different types of } \\
\text { patients and in the different phases }\end{array}$ & $9(8-9)$ & 95.5 & First round agreement \\
\hline 36. Each patient should have a specific physician responsible for his/her follow-up & $9(8-9)$ & 92.1 & First round agreement \\
\hline 37. If in palliative care, the patient should be treated by medical oncology specialists & $7(5-8)$ & 57.8 & No agreement \\
\hline $\begin{array}{l}\text { 38. The medical oncology specialist will decide as to when the patient will receive } \\
\text { symptomatic palliative care within a palliative care program }\end{array}$ & $9(7-9)$ & 87.6 & First round agreement \\
\hline $\begin{array}{l}\text { 39. Participation in the multidisciplinary tumor committee of an endocrinology / nutrition } \\
\text { specialist for screening and nutritional assessment, preoperative immunonutrition and } \\
\text { nutritional support, as well as its involvement in the follow-up of all patients for the control } \\
\text { of diabetes, pancreatic insufficiency and vitamin deficiencies, as appropriate }\end{array}$ & $8(6.5-9)$ & 75.3 & First round agreement \\
\hline
\end{tabular}

$I Q R$ interquartile range

Table 6 Section VI results: recommendations for the future

\begin{tabular}{|c|c|c|c|}
\hline & $\begin{array}{l}\text { Median } \\
\text { (IQR) }\end{array}$ & $\begin{array}{l}\text { Agreement } \\
(\%)\end{array}$ & Result \\
\hline $\begin{array}{l}\text { 40. It is recommended to create specialized diagnostic functional units with rapid circuits to } \\
\text { manage certain suspected PC defined according to the patient's risk characteristics and } \\
\text { possible alarm signals }\end{array}$ & $9(8-9)$ & 93.3 & First round agreement \\
\hline
\end{tabular}

$I Q R$ interquartile range

assess disease volume, correlates with stage and resectability, and has prognostic value after resection of the tumor $[3,5]$.

In the absence of good biomarkers, a high degree of suspicion to reach a rapid diagnosis remains crucial, especially among primary care physicians who are generally the first to treat the patient with symptoms that could suggest PC.

Panelists also agree that the initial symptoms of PC are nonspecific, not striking, or may be due to other pathologies as well. For this reason, it is possible that the first consultation with the specialist may be delayed by several months. This undoubtedly contributes to the fact that most patients (up to $80-85 \%$ ) are not diagnosed until at the very advanced stages of the disease, when the tumor has metastasized in other organs [4].

PC symptoms depend on their location (head, tail or body of the pancreas), as well as their size and stage [10]. About $60-70 \%$ are located in the head, $20-25 \%$ in the body and the tail, and the remaining $10-20 \%$ affect the pancreas diffusely [3].

Some common signs are jaundice, abdominal pain, weight loss, steatorrhoea, or newly started diabetes. Nonspecific symptoms may also occur, such as abdominal pain, nausea or vomiting [3, 10]. In this regard, the panel has agreed on two specific recommendations:
- The onset of diabetes without metabolic syndrome (especially in individuals older than 50 years), nonspecific gastrointestinal symptoms, or involuntary weight loss, may facilitate suspicion of PC.

- In primary care, the presence of jaundice in a patient aged over 40 years should be a reason to refer the patient to the emergency room. In patients aged over 60 years, weight loss associated with other gastrointestinal changes (especially abdominal pain and diarrhea), back pain, or new-onset diabetes should be a reason for referral to the specialist within 15 days.

Other classic symptoms of PC which may also arouse suspicion of the physician are depression, migratory thrombophlebitis (Trousseau's syndrome), or the sign of Courvoisier (palpable vesicle on the physical examination) $[3,14]$.

\section{Diagnostic}

Multidetector or multislice computed tomography (MCT) is the imaging technique of choice in the diagnosis and staging of PC [15, 16]. Magnetic resonance imaging and especially magnetic resonance cholangiopancreatography are techniques that may also be useful, especially in cases where MCT is inconclusive, such as in small tumors or 
Table 7 Summary of recommendations

\section{General and pre-diagnosis}

1. PC has been classically associated with a certain nihilistic medical approach. In recent years, therapeutic improvements and new treatment options justify leaving behind this skepticism in the face of more encouraging prospects

2. There are currently not enough data to support systematic screening for PC in asymptomatic patients. Since the initial symptoms are nonspecific or not very noticeable, a high degree of suspicion, especially in primary care, is crucial for a faster diagnosis of the disease

3. The occurrence of diabetes, especially in patients aged over 50 years, without metabolic syndrome, or non-specific gastrointestinal changes or involuntary weight loss may facilitate suspicion

4. In primary care, the presence of jaundice in a patient over 40 years old should be a reason to refer the patient to the emergency room. In patients aged over 60 years, weight loss with other associated clinical problems (diarrhea, abdominal pain, nausea, vomiting, constipation, or new-onset diabetes) should be a reason for referral to an specialist within 15 days

\section{Diagnosis}

5. The standard diagnostic procedure should include first steps anamnesis, physical examination, analytical and ultrasound tests

If there is a substantial delay in performing ultrasound scans, mention of the suspected PC in the application should determine an expedited scanning

If ultrasound results are not diagnostic, there must be a protocol that leads directly to performance of a MCT scan

If the ultrasound is negative but symptoms are sufficiently indicative of $\mathrm{PC}$, refer the patient to a specialist for the assessment of the case and selection of the appropriate tests

6. Suspected cases while in primary care should be referred to a hospital with multidisciplinary tumor committees with experience in the diagnosis and treatment of PC. Centers that do not have these committees should send the patient with diagnosis or clear suspicion of PC to a referral center that does. The diagnostic study in such unit should be completed within 2 weeks

\section{Treatment}

7. The treatment to be applied (or alternatively new diagnostic tests) should always be established by a multidisciplinary tumor committee. The committee should meet at least weekly

8. The multidisciplinary tumor committee should always include specialists in medical and radiotherapeutic oncology, surgery, pathology, radiology, digestive system, ecoendoscopy and nutrition/dietetics. Optionally, each center may opt for additional participation of specialists in critical care endocrinology, interventional radiology or other specialties

9. The maximum delay time to initiate treatment should not exceed the following deadlines:

Surgical treatment with curative intent: surgery should be performed in less than 15 days and no later than 4 weeks after tumor staging. When adjuvant chemotherapy is needed, it is recommended to initiate it after 3-4 weeks from the intervention, but no later than 6-8 weeks after the intervention, unless there is an insufficient recovery of the patient

In patients who are not candidates for surgery, the maximum time from staging to initiation of chemotherapy should be 7 days, or 15 days for chemoradiotherapy

In patients with borderline resectable tumors, preoperative chemotherapy or chemoradiotherapy should be started preferably in less than 15 days and no later than 4 weeks after staging

Palliative chemotherapy: no later than 7 days after staging

Follow-up

10. The type of follow-up to be performed should be defined by the multidisciplinary tumor committee. In order to avoid repetitions and redundancies, each center must establish a consensual protocol to define which specialties or units assume the follow-up of the different types of patients in the different phases. Each patient should have a specific physician responsible for their follow-up

11. Participation in the multidisciplinary tumor committee of an endocrinology / nutrition specialist for screening and nutritional assessment, preoperative immunonutrition and nutritional support, as well as its involvement in the follow-up of all patients for the control of diabetes, pancreatic insufficiency and vitamin deficiencies, as appropriate

\section{Recommendations for the future}

12. It is recommended to create specialized diagnostic functional units with rapid circuits to manage certain suspected PC defined according to the patient's risk characteristics and possible alarm signals

isointense tumors [15]. Panelists agree that ultrasound has a low sensitivity for the detection of PC [15]. However, being a non-invasive, readily available, and low-cost technique, it is often the first diagnostic technique in patients with jaundice or abdominal pain [15]. Therefore, panelists consider that ultrasound should be part of the initial diagnostic procedure along with anamnesis, physical examination, and a blood test.
The following practical recommendations are given in order to reduce the delay in performing the ultrasound and the subsequent MCT:

- The ultrasound request should specify a suspicion of PC, which should ensure a prompt scanning by the diagnostic imaging service. 
- When there is clinical suspicion of PC and ultrasound is not conclusive, there must be a protocol that leads directly to MCT.

- If accessibility for explorations is limited (jaundice or acute pain that causes suspected pancreatitis) the patient may be referred to the emergency unit for urgent diagnostic tests.

Panelists emphasize that a negative ultrasound does not rule out PC and that if the symptoms are sufficiently indicative, the patient should be referred to the specialist for MCT test.

Although the panelists were not explicitly asked, the scientific committee behind this consensus considers that the maximum delay in performing an ultrasound from a suspected PC should not exceed 10-15 days. Likewise, after an inconclusive ultrasound, MCT should not be delayed beyond 10-15 days.

The centralization of patients with $\mathrm{PC}$ in reference centers, with more patients and more experience in the treatment of pathology, improves their prognosis and survival [6, 17]. Similarly, panelists agree on the need for reference centers that have multidisciplinary tumor committees, where patients with clear suspicion or with a confirmed PC should be referred.

Panelists agree that multidisciplinary tumor committees should include specialists in medical and radiotherapy oncology, hepatobiliary surgery, pathology, radiology, digestive tract, echo-endoscopy, and nutrition/dietetics. Optionally, each center may opt for the additional participation of specialists in critical care, endocrinology, interventional radiology, or other specialties.

There is also consensus that in these units, a diagnostic study should be completed within 2 weeks. This diagnostic study usually includes hemogram, biochemistry, markers such as CA 19-9, MCT, and biopsy. Regarding MCT, a specific protocol is needed to assess the connection of the tumor to mesenteric vessels and to be able to assess its resectability. Pancreas protocols are not always equal between centers but they usually include fine sections $(<3 \mathrm{~mm})$ with a multiphase technique and a posterior multiplanar reconstruction. Images are obtained in a pancreatic phase (40-50 s after contrast injection), as well as in a portal venous phase (65-70 $\mathrm{s}$ after contrast injection) $[5,15,16,18]$.

After these imaging studies, panelists consider that it is mandatory to obtain a cytological or histological sample to confirm the diagnosis of $\mathrm{CP}$, except for surgical cases in which histological examination is performed with operative samples [5]. The most recommendable technique for sampling is biopsy or cytology by aspiration with fine needle guided by echo-endoscopy [5]. This technique offers better results and is safer than thin percutaneous biopsy guided by MCT [5], although sometimes this technique is necessary in more distal tumors. Samples can also be obtained through endoscopic retrograde cholangiography [5], as in cases of obstructive jaundice, or by ultrasound-guided puncture in case of liver metastases.

\section{Treatment}

Regarding therapeutic management, it is emphasized that the multidisciplinary committee of tumors constituted in the center should establish the treatment. In addition, it is recommended that this committee should meet for decision-making at least once a week. The maximum period elapsed from the definitive diagnosis and the beginning of the treatment should be between 15 days and 1 month. Resection with curative intent will be performed in approximately $20 \%$ of patients. Eighty percent of patients will be candidates for palliative treatment with chemotherapy or chemoradiotherapy [3]. The panel has established deadlines between the decision making process and the initiation of treatment. These deadlines depend on the type of treatment to be introduced and can be summarized as follows:

- Surgical treatment with curative intent: surgery should be performed in less than 15 days and no later than 4 weeks after tumor staging. When adjuvant chemotherapy is needed, it is recommended to initiate it after 3-4 weeks from the intervention, but no later than 6-8 weeks after the intervention, unless there is an insufficient recovery of the patient.

- In patients who are not candidates for surgery, the maximum time from staging to initiation of chemotherapy should be 7 days, or 15 days for chemoradiotherapy.

- In patients with borderline resectable tumors, preoperative chemotherapy or chemoradiotherapy should be started preferably in less than 15 days and no later than 4 weeks after staging.

- Palliative chemotherapy: no later than 7 days after staging.

The panelist also agreed that treatment, both surgical and medical, should be performed in tertiary centers that have teams with experience in this pathology and have access to all complementary services that may be necessary: ICU, interventional vascular treatment, etc.

\section{Follow-up}

Finally, the last recommendations of the panelists address the follow-up of the patients. It is recommended that each center should establish a consensual protocol to define which specialties or units assume the patient's follow-up at 
each stage. This recommendation tries to avoid repetition and redundancy in patient's follow-up, since there may be many physicians involved. However, each patient must have a specific physician responsible for his or her followup.

The panel did not discuss how this follow-up should be carried out, probably because the patients and treatments are heterogeneous and the type of follow-up is highly variable. In patients who underwent surgical resection, US National Comprehensive Cancer Network guidelines recommend a clinical assessment by MCT and CA 19-9 levels every 3-6 months for 2 years and then every 6-12 months [5]. However, probably due to the poor prognosis of the disease, there is no evidence that follow-up with MCT improves survival $[3,5,19]$. In general, follow-up should focus on symptom control, nutrition, and psychosocial support [3].

The only item that was not consensual in the questionnaire was the one that suggested that in palliative treatment specialists in medical oncology should treat the patient. This point has been conflicting, probably because the palliative treatment may include not only chemotherapy or radiotherapy, which would involve medical and radiotherapy oncology, but also palliative surgery, drainage, prosthesis, pain treatment, etc. which would then include surgeons, interventional radiologists, anesthetists, and others. In this sense, the opinion of the scientific committee is that in cancer treatment with palliative intent, the patient should be treated by those specialists that the multidisciplinary tumor committee considers more appropriate in each case according to the predominant clinic.

\section{Limitations}

This consensus suffers from the limitations inherent in the Delphi methodology, specifically the selection of the panel of experts and the limitation of the method to underline particular evaluations of the experts. The panelists have been selected by the scientific societies themselves, which contributes to limit the selection bias of the participants. It should be taken into account that this consensus is strengthened by recommendations from all the specialties involved in the management of PC. Moreover, the sponsors of the consensus have not participated in any phase of consensus development, nor in the analysis, interpretation of results, or writing of the final document.

\section{Conclusions}

In summary, this consensus gives practical recommendations aimed at improving the overall management of the patient with PC. The consensus emphasizes the importance of the awareness of primary care physicians about possible signs of alarm. It also recommends shortening the maximum time in the diagnostic process and initiation of treatment. Finally, it highlights the importance of centralizing management in reference centers with specialized multidisciplinary units.

The work between cooperative groups of different specialties involved in this pathology can improve the approach to this complex disease, including its diagnostic methods, treatments with curative intention, disseminated disease, support treatment, and nutrition.

The present consensus can facilitate the early diagnosis of patients and improve the surgical and medical-palliative possibilities of the patients affected by this complex pathology.

Acknowledgements The authors and scientific societies involved in this study want to make a special mention and show their appreciation to participating panelists who voted according to the Delphi methodology and whose opinion has been crucial to elaborate this consensus document. Spanish Society of Medical Oncology: Carlos Gómez Martín, Fernando Rivera Herrero, Joan Maurel Santasusana, Teresa Macarulla Mercadé, José M. Vieitez del Prado, Mercedes Salgado Fernández, Berta Laquente Sáez, Roberto Pazo Cid, Carmen Guillén Ponce y Andrés Muñoz Martín. Spanish Society of Anatomic Pathology: Laura G. Pastrián, Marisa Gómez Dorronsoro, Elvira González Obeso, M. del Carmen Gómez Mateo, Beatriz Madrigal Rubiales, Isabel Amengual Antich, Lupe López Alonso y M. Mercedes Hernando Martín. Spanish Society of Radiotherapy and Oncology: Ana Hernández, Iñigo San Miguel Arregui, Jordi Trilla, Juan Quirós Rivero, Virginia Morillo Macias, Amalia Palacios Eito y Marina Gómez Espi. Spanish Society of General and Family Physicians: Carmen Rocío García García y Violeta Rodríguez Rodríguez. Spanish Society of Endrocrinology and Nutrition: Inmaculada Peiró Martínez, Sara Torrejón Jaramillo, Rocío Puig Piña, Ana Cantón Blanco, Ana Zugasti Murillo, Montserrat Gonzalo Marín, Izaskun Olaizola y Maria Ballesteros Pomar. Spanish Society of Surgical Oncology: Joan Figueras Felip, Xabier Arteaga Martín, Vicente Artigas Raventós, José Manuel Asencio Pascual, Pere Bretcha Boix, David Pacheco Sánchez, Fernando Pereira Pérez, José Manuel Ramia Ángel y Luis Secanella Medayo. Spanish Society of Medical Radiology/Spanish Society of Abdominal Radiology: Enrique Ramón Botella, Miguel Ángel Corral de la Calle, M. Dolores García González, Jose Ramón Olalla Muñoz, Saturnino González Ortega, Anne Darnell, Gonzalo Tardaguila de la Fuente, M. del Rosario Pastor Juan, Xavier Merino Casabiel y Carmen de Juan García. Spanish Society of Surgeons: Luis Sabater Orti, Miguel Ángel Gómez Bravo, Angel Moya Herraiz, José Ignacio Poves Prim, Miguel Ángel Suarez, Fernando Rotellar Sastre, Inmaculada Ruiz Montesinos, Luis Díez Valladares, Mario Serradilla Martín, Fabio Ausania. Spanish Society of Family and Community Medicine: Fernando López Verde, Carmen Vela Vallespín, Aurelio Duque Valencia y Rubén Villa Estébanez. Spanish Society of Primary Care Physicians: Carlos Siljestrom y Mercedes Camarasa Vidal. Spanish Gastroenterology Association: Antonio López Serrano, Belén González de la Higuera, Lucas Ilzarbe Sanchez, Xavier Molero, Jaume Boadas Mir, Judith Millastre Boco, Emma Martínez Moneo, José Lariño Noia, Jesús María Urman Fernández, Enrique de Madaria Pascual. Spanish Society of Internal Medicine: Emilio Casariego Vales, Ricardo Gómez Huelgas, Gregorio Tiberio López, Juan José Jusdado, Carlos Dueñas Gutiérrez, Alberto Ruiz Cantero, Roser Solans, Elena Fernández Bouza y Antonio Martínez Riera. The authors would like to thank Springer Healthcare Iberica and Dr. Pablo Rivas for editorial support. 


\section{Cmpliance with ethical standards}

Conflict of interest Authors declare no conflicts of interest.

Funding Celgene and Baxalta (now Shire) have supported this consensus. However, they have not participated in its development, analysis, interpretation, or writing.

Protection of people and animals The authors affirm that no experiments have been performed on humans or animals for this research.

Rights to privacy and informed consent The authors affirm that no patient data appear in this article.

\section{References}

1. Carrato A, Falcone A, Ducreux M, Valle JW, Parnaby A, Djazouli K, et al. A systematic review of the Burden of Pancreatic Cancer in Europe: real-world impact on survival, quality of life and costs. J Gastrointest Cancer. 2015;46(3):201-11. doi:10.1007/s12029-015-9724-1.

2. Malvezzi M, Bertuccio P, Levi F, La Vecchia C, Negri E. European cancer mortality predictions for the year 2014. Ann Oncol Off J Eur Soc Med Oncol. 2014;25(8):1650-6. doi:10.1093/annonc/mdu138.

3. Ducreux M, Cuhna AS, Caramella C, Hollebecque A, Burtin P, Goere D, et al Cancer of the pancreas: ESMO clinical practice guidelines for diagnosis, treatment and follow-up. Ann Oncol Off J Eur Soc Med Oncol. 2015;26(Suppl 5):v56-68. doi:10.1093/annonc/mdv295.

4. He XY, Yuan YZ. Advances in pancreatic cancer research: moving towards early detection. World J Gastroenterol. 2014;20(32):11241-8. doi:10.3748/wjg. v20.i32.11241

5. NCCN Clinical Practice Guidelines in Oncology (NCCN Guidelines ${ }^{\circledR}$ ). Pancreatic Adenocarcinoma. Version 2.2016. https://www.nccn.org/professionals/ physician_gls/pdf/pancreatic.pdf.
6. Gooiker GA, Lemmens VE, Besselink MG, Busch OR, Bonsing BA, Molenaar IQ, et al. Impact of centralization of pancreatic cancer surgery on resection rates and survival. Br J Surg. 2014;101(8):1000-5. doi:10.1002/bjs.9468.

7. Jones J, Hunter D. Consensus methods for medical and health services research BMJ (Clinical research ed). 1995;311(7001):376-80.

8. The RAND/UCLA Appropriateness Method User's Manual I RAND. http:// www.rand.org/pubs/monograph_reports/MR1269.html.

9. Chang DK, Merrett ND, Biankin AV. Improving outcomes for operable pancreatic cancer: is access to safer surgery the problem? J Gastroenterol Hepatol. 2008;23(7 Pt 1):1036-45. doi:10.1111/j.1440-1746.2008.05471.x.

10. Eskander MF, Bliss LA, Tseng JF. Pancreatic adenocarcinoma. Curr Probl Surg. 2016;53(3):107-54. doi:10.1067/j.cpsurg.2016.01.001.

11. de Mestier L, Danset JB, Neuzillet C, Rebours V, Cros J, Soufir N, et al. Pancreatic ductal adenocarcinoma in BRCA2 mutation carriers. Endocr Relat Cancer. 2016;23(10):T57-67. doi:10.1530/erc-16-0269.

12. Lu C, Xu CF, Wan XY, Zhu HT, Yu CH, Li YM. Screening for pancreatic cancer in familial high-risk individuals: a systematic review. World $\mathrm{J}$ Gastroenterol. 2015;21(28):8678-86. doi:10.3748/wjg.v21.i28.8678

13. Vasen H, Ibrahim I, Ponce CG, Slater EP, Matthai E, Carrato A, et al. Benefit of surveillance for pancreatic cancer in high-risk individuals: outcome of long-term prospective follow-up studies from three european expert centers. J clin oncol off j Am Soc Clin Oncol. 2016;34(17):2010-9. doi:10.1200/jco.2015.64.0730.

14. Wolfgang CL, Herman JM, Laheru DA, Klein AP, Erdek MA, Fishman EK, et al. Recent progress in pancreatic cancer. CA Cancer J Clin. 2013;63(5):318-48. doi:10.3322/caac.21190

15. Lee ES, Lee JM. Imaging diagnosis of pancreatic cancer: a state-of-the-art review. World J Gastroenterol. 2014;20(24):7864-77. doi:10.3748/wjg.v20.i24.7864.

16. Pietryga JA, Morgan DE. Imaging preoperatively for pancreatic adenocarcinoma. J Gastrointest Oncol. 2015;6(4):343-57. doi:10.3978/j.issn.2078-6891. 2015.024.

17. Lemmens VE, Bosscha K, van der Schelling G, Brenninkmeijer S, Coebergh JW, de Hingh IH. Improving outcome for patients with pancreatic cancer through centralization. Br J Surg. 2011;98(10):1455-62. doi:10.1002/bjs.7581.

18. Al-Hawary MM, Francis IR, Chari ST, Fishman EK, Hough DM, Lu DS, et al Pancreatic ductal adenocarcinoma radiology reporting template: consensus statement of the Society of Abdominal Radiology and the American Pancreatic Association. Radiology. 2014;270(1):248-60. doi:10.1148/radiol.13131184.

19. Witkowski ER, Smith JK, Ragulin-Coyne E, Ng SC, Shah SA, Tseng JF. Is it worth looking? Abdominal imaging after pancreatic cancer resection: a national study. J Gastrointest Surg Off J Soc Surg Aliment Tract. 2012;16(1):121-8 doi:10.1007/s11605-011-1699-z. 